\title{
Fliegende Bauten
}

Fliegende Bauten sind bauliche Anlagen, die geeignet und bestimmt sind, wiederholt aufgestellt und abgebaut zu werden. Sie sind nicht für einen dauerhaften Betrieb vorgesehen, da die Anschlüsse nicht fest installiert werden (flexible Kabel, Wasserschläuche, etc.).

Für die Fliegenden Bauten gelten besondere Vorschriften, diese sind in den jeweiligen Landesbauordnungen (LBO), der Versammlungsstättenverordnung (VstättV) in den Versionen der Länder (o. V. 2017) sowie in Technischen Regeln und Normen geregelt.

Beispiele: Bierzelte, Fahrgeschäfte, Tribünen.

Bevor Fliegende Bauten das erste Mal aufgestellt werden, ist eine Ausführungsgenehmigung erforderlich (u. a. nicht bei Zelten unter 75 qm Größe). 